\title{
A CRIAÇÃO DO O ESTADO DE S. PAULO (OESP) E A SUA CONSOLIDAÇÃO EM UMA PERSPECTIVA HISTÓRICA
}

\section{THE CREATION OF O ESTADO DE S. PAULO (OESP) AND YOURS CONSOLIDATION IN A HISTORICAL PERSPECTIVE}

\author{
Thiago Fidelis ${ }^{*}$
}

\begin{abstract}
RESUMO
O presente artigo tem como objetivo explanar sobre a criação e consolidação do jornal $O$ Estado de $S$. Paulo (OESP), organizado por membros do recém-fundado Partido Republicano (PR), no início da década de 1870. Embora também com finalidade política, a estruturação desse periódico é ligada também às questões econômicas e sociais, uma vez que seus principais acionistas eram cafeicultores e fazendeiros paulistas, que viam nesse órgão uma forma de representatividade de suas demandas perante à sociedade. Originalmente chamado de A Província de S. Paulo (APSP), na passagem do século XIX para o XX a publicação passou a ter seu nome atual e também se organizou em uma perspectiva mais comercial, embora mantendo os aspectos políticos em voga. Assim, a breve análise desse texto vai até o fim do Estado Novo, passando pelos dois principais nomes por trás da organização da cultura política presente nos textos: Júlio de Mesquita e Júlio de Mesquita Filho.
\end{abstract}

Palavras-chave: O Estado de S. Paulo; Júlio de Mesquita; Júlio de Mesquita Filho; Sociologia da Comunicação.

\begin{abstract}
This article aims to explain the create and the consolidation of the newspaper $O$ Estado de S. Paulo (OESP), organized by members of the Partido Republicano (PR), in the beginning of the 1870's decade. Although also with political purpose, the structuring of this newspaper is linked to economical and social issues, since has yours mains shareholders were coffe growers and farmers, who saw in this newspaper a form of representation of their demands towards the society. Originally called A Provincia de S. Paulo (AFSP), in the passage of the XIX century to the $\mathrm{XX}$ the newspaper changed its current name and also structured itself into a commercial perspective, while keeping the political aspects in vogue. So, the brief analysis of this text goes to the end of the Estado Novo, passing through the two main names behind the organization of the political culture presents in the texts: Júlio de Mesquita and Júlio de Mesquita Filho.
\end{abstract}

Keywords: O Estado de S. Paulo; Júlio de Mesquita; Júlio de Mesquita Filho; Sociology of Communication.

"Doutorando em Ciências Sociais pela Unesp. 


\section{INTRODUÇÃO}

Parte significativa da política do Segundo Reinado (1840/1889) foi estruturada pelos dois grandes grupos políticos da época, os liberais e conservadores. Essas agremiações partidárias, membros ativos no governo (alternando postos, ora como situação e ora como oposição), passaram a intensificar as disputas entre si, principalmente, a partir da expansão da produção de café, com a intensa divisão entre os produtores da região do Vale do Paraíba, grupos conservadores ligados às bases monárquicas e os investidores da região do Oeste Paulista, com perspectivas distintas que não eram mais contempladas em nenhuma dessas organizações (CASALECCHI, 1987).

Em 18 de abril de 1873, foi fundado o PR, congregando inúmeros nomes da cafeicultura paulista (sobretudo os produtores do Oeste Paulista). Embora não oficialmente, o jornal Correio Paulistano (CP) passou a publicar textos e dar cobertura praticamente oficiosa ao grupo, que procurava ser uma via opositora ao binômio partidário predominante, como demonstrou a capa da edição do dia 25 de abril:

Conforme referimos (...) deu-se em Itú, a 18 do corrente, a convencionada reunião de republicanos da provincia; brilhantissimo e animador concurso a que foram presentes para mais de duzentos republicanos (...) Foi imponente, largo e sério o debate que preoccupou a reunião durante mais de tres horas, no indicado dia 18 , de 5 da tarde até $81 / 2$ da noute mais ou menos (...) (CP, A reunião republicana de Itú, 25/04/1875).

No entanto, mesmo com a cobertura do jornal bastante intensa (o órgão passou a ser oficial do partido, de fato, a partir de 1890), dois anos depois da fundação da agremiação foi criado um novo periódico. Segundo o historiador Nelson Werneck Sodré, vários dos membros do grupo do recém-fundado PR queriam ter em mãos uma publicação que não fosse fiel signatário do partido, possuindo certa independência para, inclusive, criticar medidas que pudessem ser endossadas pela cúpula partidária, mas não por todos os membros (SODRÉ, 1966, p. 259). Assim, nesse ano, foi fundada A Província de São Paulo (APSP), sendo que seus principais objetivos foram apresentados em sua primeira edição, em 04 de janeiro:

Mais uma folha diaria vem offerecer á província de S. Paulo campo livre aos debates tão necessa- rios para solução de problemas importantes que interessam o seu desenvolvimento moral e material (...) novo jornal se apresente em condições de poder influir directamente no progresso do paiz e na educação do povo, e habilital-o a ser, como um escriptordistincto já definio a jornal, "o cuidadoso expositor de todos os productos da intelligencia humana, a escola em que entram todos aquelles que sabem soletrar." (APSP, 04/01/1875).

Além de outros textos explicativos, nessa edição o periódico trouxe todas as informações referentes à sua formação: os primeiros redatores foram o promotor público e jornalista Américo de Campos (que ficou no jornal até 1884, quando saiu para fundar outro periódico, o Diário Popular) e o político Francisco Rangel Pestana (que ficou no jornal até 1891). O administrador geral foi o jornalista português José Maria Lisboa (que também deixou o periódico em 1884 e foi um dos fundadores do Diário Popular, junto com Américo de Campos).

Ao checar os nomes dos primeiros acionistas envolvidos na organização do capital inicial do jornal (disponível na primeira página do jornal da primeira edição), fica bastante explícito que o periódico foi composto, basicamente, por pessoas ligadas à cafeicultura e ao comércio do estado paulista, com uma pauta política bastante alinhada com o recém-fundado PR (embora enfatizando, sempre, que não era partidário e que não possuía vínculo com nenhum outro grupo, seja de ordem política ou econômica), além de indicar que o diário já iniciava suas atividades com vasto capital, em uma perspectiva para atingir um público considerável (SODRÉ, 1966, p. 259-260).

Dentro da perspectiva apresentada, o principal objetivo desse artigo é pensar a criação desse periódico, indicando em perspectiva histórica como essa publicação consolidou suas bases, levando em conta a trajetória de seus principais donos e ideólogos, responsáveis pela cultura política exposta na publicação: Júlio de Mesquita e seu filho, Júlio de Mesquita Filho, sendo que esse trabalho acompanhou e problematizou os principais aspectos referentes a esses assuntos até o fim do Estado Novo, em 1945.

Como método, a análise utilizada pautou-se em uma extensa revisão bibliográfica sobre o assunto, bem como a verificação de várias edições ao longo dos quase 70 anos nos quais o texto abrange. Levando em conta a extensão do artigo e seu escopo, foi feita 
a escolha de dar maior enfoque à trajetória dos dois principais nomes envolvidos no direcionamento do jornal nesse período, buscando a relação entre suas culturas políticas e a estrutura construída do OESP.

Em linhas gerais, o periódico lutou pelas principais bandeiras republicanas em suas páginas nesse período final da Monarquia, sendo bastante enfáticos na cobertura de vários fatos importantes. $\mathrm{Na}$ data da abolição da escravatura, por exemplo, APSP foi deveras explícito em sua posição:

\section{GLÓRIA Á PATRIA}

Está extincta a escravidão no Brazil (...) A libertação dos escravos faz-se no Brazil por um acentuado movimento da opinião, pela capitulação franca das ultimas forças de resistencia, pela desagregação dos elementos conservadores, mas em plena paz, sem perturbação da ordem, pelo congraçamento dos combatentes da vespera (...) Gloria á Patria que se engrandece libertando os pacientes cooperadores do seu progresso! (APSP, GLÓRIA Á PATRIA, $13 / 05 / 1888)$.

Além de defender a abolição da escravatura, APSP já publicava (com grande periodicidade) textos relacionados à defesa da instituição do sistema republicano no país. Na edição consequente à Proclamação da República (15/11/1889), o periódico quebrou o protocolo ao publicar uma capa distinta do padrão, demonstrando o impacto que tinha essa data para o jornal (e, na visão de seus proprietários, para o país).

Nessa edição "comemorativa", APSP também foi bastante enfático em relação ao seu posicionamento sobre a temática:

Notícias da Corte annunciam a proclamação da Republica - a forma de governo que exprime o sentimento nacional!

Unamo-nos! para garantir a ordem, porque o novo regime nasce da livre manifestação popular!

Povo! o primeiro dever do republicano neste momento é ser calmo, previdente, justo, tolerante, para ser energico na organisação.

A Republica significa a paz, o progresso, a civilisação.

Unamo-nos sem distincção de partidos para firmarmos esse novo regime que nos ha de trazer a gloria, a grandeza e a felicidade!
Viva a Republica! (AFSP, 15 DE NOVEMBRO DE 1889 GLORIOSO CENTENARIO DA GRANDE REVOLUÇÃO PROCLAMAÇÃO DA REPUBLICA BRAZILEIRA, 16/11/1889).

No período republicano que se seguiu, APSP continuou bastante ativo em relação aos acontecimentos políticos nacionais e referentes ao próprio estado. Em 1890 o jornal passou a chamar-se $O$ Estado de $S$. Paulo e, no final do século XIX, boa parte dos acionistas que iniciaram o periódico já tinham vendido suas partes, sendo que o controle do diário, de fato, estava nas mãos de Júlio de Mesquita, jovem advogado natural de Campinas que começou a trabalhar em 1885 (assumira a Redação do jornal em 1888 e o comando geral, dois anos depois) por indicação de Alberto Salles (seu sogro, irmão de Campos Salles), que havia entrado posteriormente na sociedade.

Antes do período republicano, Júlio de Mesquita já tinha exercido o cargo de vereador em Campinas. Logo após a Proclamação tornou-se secretário particular do primeiro presidente do estado paulista ${ }^{1}$, Prudente de Morais (que tornar-se-ia o dirigente máximo da política brasileira, em 1894). Em 1891, foi eleito deputado federal e, até o fim da segunda década do século XX, foi eleito sucessivas vezes (5 legislaturas) deputado estadual e também senador estadual por um mandato ${ }^{2}$.

Embora filiado e com forte ligação ideológica com o Partido Republicano Paulista (PRP - era uma das seções estaduais do Partido Republicano), Júlio de Mesquita sempre foi muito crítico em relação a várias decisões tomadas pelo partido, se opondo em inúmeros momentos à direção majoritária da agremiação como, por exemplo, contra a política dos governadores exercida pelo presidente Campos Salles (1898/1902), além de discordar publicamente de vários atos relacionados aos governos federal e estadual, em momentos distintos.

Portanto, OESP sempre manteve uma postura bastante crítica com os presidentes (e os governos em geral), sendo que o principal canal opinativo era a seção Notas e Informações, na qual o editor-chefe do jornal expunha sua visão em relação aos acontecimentos nacionais e mundiais (sobretudo as

\footnotetext{
${ }^{1}$ Até a Constituição de 1934 , os governadores dos estados eram chamados dessa forma.

${ }^{2} \mathrm{Na}$ Constituição paulista de 1891, a Câmara era dividida entre deputados e senadores do próprio estado, diferentemente da Constituição atual.
} 
políticas). Embora não assinasse seus textos (prática a qual perdura no impresso até os dias atuais), Júlio de Mesquita escreveu boa parte das publicações nessa seção, procurando especificar com essa ação, segundo CALDEIRA (2015, p. 45-46), que a opinião emitida pelo periódico não era pessoal, mas sim de todo o grupo que o gerenciava.

Além disso, o jornal passou a cobrir vários acontecimentos internacionais importantes, sendo que, durante a Primeira Guerra Mundial, Júlio de Mesquita publicou, semanalmente, impressões acerca dos fatos ligados à guerra, analisando o conflito e seus desdobramentos:

O que vimos e vemos é que, entre o Brasil e a Alemanha, não há paz: só compreenderíamos que entre as duas nações houvesse guerra. Da paz à guerra não se abre nenhum espaço: não existe nada aí, e tanto é certa essa inexistência que o Direito Internacional, em trezentos anos de lucubrações e cautelas para emergências sabidas, prováveis e possíveis, não viu nem previu a situação em que nos deixou a nossa diplomacia, ao recolher-se, para descansar, da fugaz atividade determinada pelo bárbaro e estúpido torpedeamento dos nossos navios mercantes (...) Nós, por enquanto, até agora, ainda não somos nada no conflito quase universal em que quase todos os países, os grandes e os pequenos, os fortes e os fracos, a Alemanha e a Bulgária, a Áustria e o Montenegro, os Estados Unidos e Portugal, o Japão e a China alguma coisa são, alguma coisa quiseram e puderam ser. Mas não repousa nesta atitude indefinida e indefinível a nossa esperança de escapar ao tributo de sangue que está pagando, às funestas divindades das desarmonias humanas, a gente que, antes de nós e com decisão superior à nossa, se revoltou contra o militarismo prussiano (OESP, BOLETIM SEMANAL DA GUERRA (DE ACCORDO COM OS NOSSOS TELEGRAMMAS, $24 / 09 / 1917)^{3}$.

Após apoiar os tenentes na tentativa de golpe em São Paulo em 1924, o jornal foi grande entusiasta da criação do Partido Democrático (PD, opositor ao PRP) (CAPELATO; PRADO, 1980, p. 23-40), uma vez que Júlio de Mesquita já havia rompido com seu partido e abandonado sua carreira política. Após seu falecimento em 1927, o periódico passou a ser controlado pelo seu primogênito, Júlio de Mesquita Filho,

${ }^{3}$ Os textos também foram organizados e publicados em forma de livro; todos os artigos podem ser encontrados em MESQUITA (2002). que nunca chegou a exercer cargos na política institucional, mas que manteve a linha de atuação do pai, próximo ao PD e fazendo franca oposição ao governo federal (PRADO, 1986, p. 16-19).

\section{JÚLIO DE MESQUITA FILHO E SEU POSICIONAMENTO POLÍTICO}

É necessário levar em conta a trajetória do novo diretor do OESP para uma reflexão mais ampla em relação aos conteúdos e às diretrizes adotadas pelo jornal. Nascido em 1892, aos 12 anos de idade foi enviado pelo pai para estudar em Portugal e, posteriormente, completou seus estudos secundários na Suíça. Contrariando a vontade paterna (que queria vê-lo médico e estabelecido na Europa), após o término dos estudos voltou ao Brasil para cursar Direito no Largo do São Francisco e, durante seus anos no curso de graduação, envolveu-se em inúmeras movimentações dentro da faculdade sempre com forte teor político (foi um dos fundadores e membros mais ativos da Liga Nacionalista de São Paulo, em 1916).

Ainda durante sua formação acadêmica, em 1915, passou a trabalhar junto com o pai, passando a colaborar com a edição vespertina do grupo, $O$ Estadinho, que abriu espaço para inúmeros nomes da imprensa como Moacir Piza, Ademar de Paula, Alexandre Ribeiro Marcondes Machado e Monteiro Lobato, além de contar com nomes experientes do próprio OESP, como Amadeu Amaral e Plínio Barreto (FERREIRA, 2002, p. 248-249). Embora o projeto não tenha durado muito tempo, circulando até 1921 (SALONE, 2009, p. 93-94), a base do jornal foi entregue para parte de seus funcionários que trabalharam por um ano no local sem pagarem taxas. Esse trabalho deu base para a criação da Folha da Manhã (que, após se fundir com outras publicações da mesma empresa, tornar-se-ia a Folha de São Paulo, em 1962) (TASCHNER, 1992, p. 36-39).

Quando assumiu a direção do jornal, Júlio de Mesquita Filho manteve as diretrizes do periódico, mas também esteve atento ao caráter econômico da publicação, expandindo cada vez mais o espaço para a publicidade e para assuntos de interesses mais gerais. Mesmo com forte enfoque político, tanto seus textos editoriais como a cobertura do jornal sempre abordavam temas relacionados à economia (principalmente à agropecuária, seguindo as bases dos fundadores do 
periódico) bem como temáticas relacionadas à saúde pública e à educação, trabalhando com autores bastante comuns na academia, mas pouco divulgados no meio jornalístico como, por exemplo Herbert Spencer, John Stuart Mill, Thomas Hobbes e Émile Durkheim, entre outros (PONTES, 2010, p. 28-29).

Tal perspectiva já se fizera notar na publicação de seu primeiro livro, em 1925, intitulado A Crise Nacional. A obra traçou um amplo panorama do Brasil, principalmente após o fim formal da escravidão e da implantação da República, pensando não só nos aspectos políticos, mas também nos culturais, voltando sua análise, principalmente, para a educação. Embora o diretor do OESP definia-se como liberal e democrata, não via com bons olhos a República da forma como fora instituída, pois concebia as instituições nacionais como bastante frágeis e a própria formação da sociedade brasileira como um problema a ser superado, questão essa que teria sido agravada após a libertação dos escravos.

Essa perspectiva (embora seu pai tenha apoiado a campanha abolicionista) foi vista como um grande problema por Júlio de Mesquita Filho, uma vez que essa movimentação acabou levando a um grande atraso no desenvolvimento da sociedade brasileira, pois esses grupos não estariam "acostumados" a viver em sociedade e essa não estaria preparada para receber esse novo contingente:

A esse afluxo repentino de toxinas, provocado pela subversão total do metabolismo político e econômico do país, haveria necessariamente de suceder grande transformação na consciência nacional que, de alerta e cheia de ardor cívico, passou a apresentar, quase sem transição, os mais alarmantes sintomas de decadência moral (...) Já agora, decorridos alguns lustros depois que a lei da libertação do elemento servil fora assinada e que os seus beneficiários haviam transposto definitivamente os portões das senzalas, desceu o nível moral da nacionalidade na proporção da mescla operada. O contato do africano, oprimido e aviltado, sem uma sobra sequer de sentimento cívico, além de quebrar a unidade psíquica indispensável às vibrações da multidão, preparou o terreno para o advento dos costumes políticos a que até hoje estamos sujeitos (MESQUITA FILHO, 1925, p. 10-13).

E embora também se colocasse como um republicano, não poupou críticas ao sistema político atual do país, tecendo imensos elogios às instituições monárquicas, em especial à ação de D. Pedro II e de vários de seus ministros, uma vez que seriam exemplos de homens probos e que se preocuparam com o desenvolvimento do país, independentemente de quais filiações partidárias possuíssem (SALONE, 2009, p. 99). Também propôs reformas políticas importantes para a melhoria das instituições brasileiras, tendo entre esses princípios a instituição do voto secreto (SALONE, 2009, p. 100), perspectiva urgente para diminuir a manipulação da escolha dos novos presidentes, entre outros aspectos.

Acompanhando de perto as movimentações relacionadas à oposição política, OESP apoiou a movimentação que levou à Revolução de 1930, louvando a libertação da política daqueles que faziam seu "mau uso". Como oposição ao governo de Washington Luís, os textos dos editoriais e a cobertura política não poupavam praticamente nenhuma movimentação do governo (o presidente já sofrera grande oposição da publicação enquanto administrador de São Paulo), sendo constantemente criticado pelas linhas escritas pelo diretor do jornal.

A eleição de 1930 foi marcada pela ruptura da aliança entre as seções paulista e mineira do PR, uma vez que ambos os grupos aliaram-se em boa parte das eleições republicanas para chegarem a vitórias eleitorais e manter a estabilidade política, conseguindo tais práticas pelo controle do voto em vários centros urbanos e com acertos com outros grupos por questões econômicas, uma vez que eram as duas regiões mais ricas do país (principalmente o estado de São Paulo, cujo principal produto, o café, era responsável por grande parte das exportações e da própria renda do Brasil).

Partindo dessa perspectiva (LEAL, 2012), era comum os indicados à cabeça da chapa de presidência serem alternados e, se na eleição de 1926 o presidente do estado paulista, Washington Luís, sucedera o antigo mandatário de Minas Gerais, Artur Bernardes, esperava-se que quatro anos depois o sucessor do presidente paulista fosse o representante mineiro, Antônio Carlos. No entanto, o indicado à sucessão pelo PRP acabou sendo o presidente de São Paulo, Júlio Prestes, fazendo com que o grupo mineiro passasse a apoiar a candidatura de seu opositor, o então presidente do estado do Rio Grande do Sul, Getúlio Vargas.

Embora o candidato gaúcho não fosse um opositor da política nacional (foi o primeiro ministro da 
Fazenda de Washington Luís e só deixou o ministério para assumir o governo estadual, em 1928), acabou liderando uma dissidência de algumas oligarquias que buscavam ascender ao poder e quebrar a hegemonia dos grupos que já dominavam o Executivo nacional há mais de trinta anos.

Tanto OESP quanto boa parte da imprensa de maior circulação nesse contexto passou a apoiar essa candidatura, observando o político gaúcho de maneira bastante positiva em suas páginas, colocando-o como um candidato não só preocupado com os conchavos políticos: "o sr. Getúlio Vargas demonstra que já tomou contacto com a realidade, percebendo emfim; que ha, no povo, outras aspirações que não as dos centros politicos e que a vida da nação não se resume na vida dos agrupamentos partidarios" (OESP, 03/09/1929).

$O$ rápido processo eleitoral foi bastante intenso e com muitas trocas de acusações, sendo que os textos de Júlio de Mesquita Filho sempre eram laudatórios ao político gaúcho e seu vice, o presidente do estado da Paraíba, João Pessoa, mantendo-se bastante crítico quanto à candidatura situacionista. Como descrito por BORGES (1979, p. 91-120), a candidatura da Aliança Liberal (grupo que unia os representantes do Rio Grande do Sul, Paraíba, Rio de Janeiro e Minas Gerais e dissidências de outras regiões, como o PD de São Paulo) era vista não como revolucionária, mas sim como renovadora. O princípio não era mudar as estruturas do país, mas sim revigorar suas instituições, fazer com que elas funcionassem de maneira correta ou ideal:

A atuação de Getúlio Vargas no seu Estado, defendendo os interesses dos grandes latifundiários de carne, arroz, trigo etc., tranqüiliza, ao que parece, os grupos oligárquicos cuja base era o latifúndio (...) Toda a prática política de Getúlio Vargas até então tinha sido a favor das oligarquias e elas parecem confiantes (...) a figura de Vargas vai substituindo as figuras de Luís Carlos Prestes, "o cavaleiro da esperança”, e de Assis Brasil, "o chefe civil da Revolução". Os dois são figuras quase que mitificadas (...) encarnam muitos dos ideais oposicionistas da época (BORGES, 1979, p. 126-128).

Após a derrota e as inúmeras movimentações que levaram à tomada do poder em novembro de 1930, OESP passou a ver com grande entusiasmo o início do governo Vargas. No entanto, a nomeação do tenente João Alberto como interventor paulista não foi encarada de maneira ideal pelo jornal, que manteve o apoio por conta da participação de vários nomes do PD no secretariado e de Plínio Barreto (um de seus diretores) como secretário de Segurança no novo governo, além de ter tido uma breve passagem, também, na chefia do Executivo estadual (BORGES, 1979, p.137-140).

No entanto, esta proximidade durou pouco tempo, uma vez que esse grupo ligado ao $\mathrm{PD}$ não conquistou a autonomia dentro do governo e as promessas de Vargas de “entregar” São Paulo aos (grupos dominantes) paulistas não foram cumpridas. As tensões foram aumentando a tal ponto que o jornal, de apoiador e crítico moderado do governo em início de 1931, passou a ser um dos grandes organizadores da Revolução de 32, em uma movimentação extremada contra o Executivo nacional e pela sua disputa por espaço político:

Não poderia caber neste palmo de prosa a descripção do enthusiasmo que, num rhythmo crescente, accelerado, vao empolgando a alma generosa dos paulistas (...) As pessoas que não tiveram a felicidade de viver comnosco esta hora excepcional, jamais poderão fazer uma idéa precisa do que seja o transbordamento cívico que empolgou nos ultimos dias, o animo habitualmente sereno das nossas populações. Os moços, então, vivem neste momento a sua grande hora, aquella que será lembrada com enternecimento ao longo de toda a existencia (OESP, 15/07/1932).

Júlio de Mesquita Filho foi um dos nomes centrais na movimentação contra o governo e, em praticamente todos os dias dos três meses de conflito contra Vargas, publicou textos e notas valorizando os combatentes e criticando intensamente o governo e seus apoiadores. Como consequência, foi preso no fim de 1932 e, posteriormente, exilado, ficando mais de um ano residindo em Portugal. Em cartas trocadas com sua esposa Marina, é bastante evidente a perspectiva política adotada e os princípios mais importantes que permeavam suas ações, indicando alguns aspectos que permeavam seu habitus, como trechos de uma carta de 12/10/1932 (quando ele estava preso, aguardando sua sentença):

Aqui estamos, na Sala da Capela da Casa de Correição, à espera que sobre nós recaiam as penas que nos reservam a ditadura. Sejam elas quais forem, pode você estar certa de que não as tememos, pois, exceto dois ou três, os demais que aqui se acham 
para cá trouxeram a disposição de ânimo que aí deixamos na memorável noite em que nos afastamos da nossa querida São Paulo (...) Vivemos da manhã à alta madrugada numa perpétua exaltação, alimentada pelas recordações destes três meses de epopéia e pelas notícias desencontradas que a todo instante nos chegam (...) E você, minha filha, como vai passando? Como tem você suportado estes duros dias em que, aos sofrimentos dos dias de luta, se vem juntar as preocupações que as incertezas do dia de amanhã despertam? Tenha coragem e ânimo. Somos moços e temos três filhos homens, que, com certeza, haveremos de educar, como paulistas dignos que hão de ser (...) Mas, apesar de tudo, tenho confiança e não me abandona a conviç̧ão de que saberei vencê-las, como nunca me abateram os revezes sucessivos da minha atribulada vida pública. A sua companhia é disso a melhor garantia (...) Se a minha prisão se prolongar, venha para cá. Estaremos, assim, próximos e com o vazio suprimido para conversarmos (...) (MESQUITA FILHO, 2006, p. 38-39)

\section{INTERVENÇÕES: CRIAÇÃO DA USP E MOVIMENTAÇÕES POLÍTICAS}

De volta ao Brasil em 1933, Júlio de Mesquita Filho encontrou a frente do estado de São Paulo seu cunhado e um dos sócios do OESP, Armando Salles de Oliveira. A nomeação foi uma das concessões feitas por Vargas após o fim da rebelião paulista para voltar a tecer relações políticas com as oligarquias paulistas (já que, no confronto, grande parte do PRP e do PD se uniu contra o atual presidente).

Mesmo ainda demonstrando ampla animosidade contra o presidente, Júlio de Mesquita Filho aceitou participar do governo paulista não na condição de secretário ou de auxiliar, mas levando a frente uma idealização que já vinha desde fins da década de 1920 (PONTES, 2010, p. 93-94), a criação de uma Universidade em São Paulo. Na obra A crise nacional, o autor já tinha discutido a necessidade de se fundar uma instituição educacional para a formação intelectual da elite paulista e brasileira, acreditando que o grupo que conduz o país deveria ser marcado pelo seu desenvolvimento intelectual, e não somente econômico:

Reestabelecido o jogo natural das instituições constitucionais pelo advento da opnião pública, restarnos-ia dar início a construção do organismo con- catenador da mentalidade nacional, representado, em todos os países de organização social completa, pelas Universidades. Sem o concurso dessa instituição secular a que a humanidade deve o melhor de suas conquistas, inútil se torna qualquer esforço no sentido de conseguir a nossa emancipação definitiva. Ao mais superficial observador não escapará, realmente, a insufficiência intelectual das chamadas classes cultas do país. Nada existe entre nós que se pareça com essas admiráveis legiões de estudiosos desinteressados, que no ambiente sereno das bibliotecas e dos laboratórios indicam, em todas as nações cultas do universo, as directrizes seguras por onde trilham confiantes os homens de acção. Essa falha lamentável a que devemos attribuir, em última anályse, a situação crítica que atravessamos, se evidência na pobreza inacreditável da nossa produção intellectual (MESQUITA FILHO, 1925, p. 3).

Em 1926, Júlio de Mesquita Filho propôs um questionário a ser publicado no OESP para os profissionais da área pedagógica em São Paulo, sobre a situação dos institutos e do próprio sistema educacional paulista. O encarregado de conduzir as entrevistas foi Fernando de Azevedo, até então crítico literário do jornal que, a partir dessa perspectiva, elaborou um grupo de perguntas e teceu contatos com inúmeras figuras de grande relevo sobre o assunto, com dezesseis questões que versaram desde o ensino básico até perspectivas para o ensino superior. As entrevistas foram publicadas em partes no jornal e o relatório final foi editado, ao longo do ano, sendo organizado, posteriormente (e de maneira mais abrangente), no livro A educação na encruzilhada, ainda em 1926.

De maneira geral, o relatório reforçou a visão já indicada pelo diretor do periódico em sua obra, expondo que o ensino em São Paulo era fragmentado, com forte influência política e orientado por interesses escusos, sem pensar em melhorias para os alunos (e, consequentemente, para o Estado e para o país):

Nestas condições só por milagre se poderia ter (em São Paulo) um aparelho de ensino harmônico e integral, posto pela legislação a serviço de claros intuitos sociais e educativos e com bastante plasticidade de adaptação às correntes renovadoras do pensamento moderno. Mas, se de um lado, como se vê, tem faltado a consciência da gravidade e complexidade do problema, abordado quase sempre de afogadilho, em tropelias burocráticas, sem colaboração de técnicos de responsabilidades definidas e sem debate público, por outro lado, ainda não se 
fez sentir entre nós, da parte dos dirigentes, aquilo que se pode chamar "uma política de educação" norteada não por homens mas por princípios. Nada que denuncie um grande ideal orientador formado no sentido profundo das realidades e necessidades nacionais e vivificado ao sopro das ideias científicas de educação. Por isso, com sucederem no poder, homens do mesmo partido, não se criou sequer o "espírito de continuidade" bastante temperado na forja de ideais comuns, para desenvolver, com esforço pertinaz e ininterrupto, e no mesmo sentido, uma política de cultura, de bases sólidas, de espírito marcadamente nacional e de objetivos precisos (AZEVEDO, 1960, p. 40).

O resultado do relatório de Fernando de Azevedo e toda a mobilização em torno do questionário demonstraram uma das principais características do editor e principal "ideólogo" do OESP, uma espécie de intelectual orgânico da imprensa paulista: sua crença na educação como forma de desenvolvimento e evolução do país (CAPELATO, 1989, p. 148-149). Suas experiências na Europa e sua formação acadêmica causaram-no profundas reflexões e, desde então, o assunto nunca o abandonou (embora boa parte de sua produção nos jornais e em livros versasse, diretamente, sobre política).

Pensando a educação sempre como um projeto de orientação das massas, Júlio de Mesquita Filho indicou a Armando Salles de Oliveira quando voltou do exílio que, em linhas gerais, o mais importante naquele momento para São Paulo era a criação de uma Universidade, que fosse integrada ao Ensino Secundário e que atendesse aos pontos que foram levantados no relatório, na década de 1920 (SALONE, 2009, p. 159).

Em conjunto com o interventor e com Fernando de Azevedo (que, naquele momento, ocupava a direção da Instrução Pública no Estado), dedicou-se a estruturar o planejamento desse novo centro de ensino, desde o espaço físico da instituição até às possíveis bases dos currículos dos cursos que seriam oferecidos. O diretor do OESP tinha em mente trazer ao Brasil uma espécie de "sopro" de civilização, apresentando autores que ele tinha lido (muitas vezes por conta própria) e ainda pouco debatidos nos meios acadêmicos brasileiros, além de pesquisas e novas linhas científicas que nasciam ou que já eram consolidadas na Europa e ainda eram pouco ou nada conhecidas no Brasil (PONTES, 2010, p. 41-45).

A partir dessas movimentações, o decreto $n^{\circ}$ 6.283 de 25 de janeiro de 1934 deu origem formal à Universidade de São Paulo (USP), que congregou vários institutos existentes em São Paulo para dialogarem entre si e dar margem a um grande centro de estudos e pesquisas na cidade. $\mathrm{O}$ decreto foi bastante valorizado nas páginas do jornal, como publicado na seção Notas e Informações, dois dias depois do documento oficial:

A Universidade é o complemento natural da obra de cultura em que S. Paulo está empenhado desde que conquistou, com a Republica, a sua autonomia (...) Sem ella, não chegariamos tão cedo, se algum dia chegassemos, a ser o laboratorio de investigações scientificas e o centro de alta e irradiante intellectualidade que precisamos ser, que a nossa missão historica nos obriga a sermos (...) Seria difficil, senão impossivel, conseguirmos realizar, fôra de uma organisaçãouniversitaria, aquelle vasto programa de cultura individual e de acção social synthetisado nos breves articulados em que se expuzeram, no decreto de hontem, os fins da Universidade de S. Paulo: o progresso da sciencia pelo desenvolvimento das pesquisas; o enriquecimento do espirito, e a felicidade collectiva pelo ensino systematisado de todos os conhecimentos de utilidade geral, ou de nobres e desinteressadas finalidades intellectuaes: a formação de especialistas em todos os ramos de cultura technica bem como de profissionaes de escol em todos os officios e mistéres de base scientifica e artistica; a vulgarisação das sciencias, das letras e das artes por meio de cursos syntheticos, conferencias, palestras, difusão pelo radio, filmes scientificos e por outras fórmas já existentes ou que venham a existir (...) (OESP, Notas e Informações, 27/01/1934).

Ficou bastante explícita no editorial (como também já estava em A Crise Nacional) uma quase predestinação que o jornalista via à "missão civilizadora" de São Paulo em relação ao Brasil. Além disso, a quase devoção do diretor do OESP em relação à cultura europeia e como a intelectualidade brasileira deveria procurar seguir os passos já consolidados dos pesquisadores do Velho Continente deram o tom das primeiras atividades do mais novo centro de estudos no país.

Por conta disso, teve autonomia do interventor paulista para realizar um plano também já anunciado, que foi a contratação de professores estrangeiros para 
os institutos que compunham a faculdade. Depois de contatos e breves viagens para a Europa, o diretor do OESP conseguiu contratar um grupo de jovens professores (e que viriam a ser reconhecidos como referências em suas áreas) que se aventuraram a lecionar em terras abaixo da Linha do Equador, como por exemplo o casal de antropólogos Claude e Dinah Levi-Strauss, o historiador Fernand Braudel e o sociólogo Roger Bastide, entre inúmeros outros intelectuais de vários países diferentes (SALONE, 2009, p. 169178). É importante destacar também que foram usados critérios não só acadêmicos, mas também políticos, uma vez que tanto o governador quanto seu cunhado eram contrários (principalmente Júlio de Mesquita Filho) ao fascismo e aos regimes autoritários que se consolidavam na Europa, nesse contexto.

Assim, para as disciplinas de formação de ciências humanas foram contratados, preferencialmente, pesquisadores franceses, já que o país era a referência para boa parte das discussões acadêmicas nessa área. Para pesquisadores italianos, alemães e portugueses (países com governos de caráter totalitário e autoritário), as áreas privilegiadas foram as de ciências exatas, uma vez que os estudos dessas disciplinas nesses países já eram bem avançados (em especial na Alemanha) e também eram conteúdos que não envolviam, necessariamente, discussões políticas (PONTES, 2010, p. 130-132).

Ele também defendeu a criação de outras universidades no Brasil, indicando mais duas principais, a primeiro momento: uma no Norte e outra no Sul do país. Tal aspecto seria fundamental para a formação de uma elite cultural, a nível nacional, que ajudaria o país a desenvolver-se. Tendo ideias bastante convergentes com a do filósofo Herbert Spencer, Júlio de Mesquita Filho enxergou na mobilização de um centro superior de estudos uma forma de intervenção direta na evolução do país, forma essa que não passava diretamente pela política, mas dependia dela para sua consolidação.

Partindo desse princípio, principalmente a elite econômica do país, deveria ter acesso ao ensino de qualidade, uma vez que esse grupo demonstrava (na visão do diretor do OESP) uma profunda anomia intelectual, não tendo praticamente formação cultural alguma e, para combater tal perspectiva (e fazer com que o Brasil crescesse de maneira correta), seria essencial o desenvolvimento de uma educação de qualidade no país:
JMF expõe (...) a crença no primado da educação para moldar a sociedade à imagem e semelhança daquilo que vira na Europa nos anos de formação. Seus pontos de partida, voto secreto, democracia e universidade, são os elementos fulcrais para a queda da velha oligarquia que dominara, quase incontrastável, o aparato estatal desde a proclamação da República. Cabia a uma nova elite, baseada no conhecimento e na meritocracia, levar adiante as reformas necessárias para modernizar o país - ainda que se discuta o grau de modernização e as formas de inclusão de massas, vistas, naquele momento histórico, com desconfiança pelas agremiações que tratavam o restrito debate político. De qualquer modo, JMF foi pioneiro ao abordar um tema antes vislumbrado como menor, desimportante ou, na melhor das hipóteses, um assunto a ser discutido após a tomada de medidas emergenciais ante a crise político-econômica que violentamente irrompia na década de 1920. Para Mesquita, a questão da reforma do Estado era menos relevante que a reformulação do pensamento dos brasileiros (...) (SALONE, 2009, p. 111)

E, além desse ponto, era necessário educar os mais abastados para conduzir o povo para o caminho "certo". Na perspectiva do diretor do OESP (e também de vários outros nomes, seja da imprensa ou da própria intelectualidade paulista), Vargas tentava ocupar esse espaço que a elite deixara para organizar as massas, fazendo com que essas passassem a venerá-lo e valorizar o Estado em detrimento do individual, o coletivo em relação à singularidade:

Os liberais paulistas acreditavam, como Ortega y Gasset, que a ascensão das massas contra as elites representava o grande perigo da época contemporânea, e daí a ênfase no fortalecimento das elites ("elites bem pensantes") para que pudessem assumir as responsabilidades devidas perante elas. Os esforços de Vargas e de seus adeptos na conquista (e controle) das massas foram entendidos como incentivo à rebelião destas contra as elites (CAPELATO, 1989, p. 195).

\section{MOVIMENTAÇÕES POLÍTICAS E A POSSÍVEL CANDIDATURA DE ARMANDO SALLES DE OLIVEIRA}

Nesse contexto estava ocorrendo a Assembleia Constituinte, cujos representantes tinham sido eleitos em 1933 e os trabalhos prolongaram-se até o 
ano seguinte, culminando finalmente com uma nova Constituição. O jornal aproximou-se novamente da política de Vargas e apoiou-o em algumas ações em seu governo, principalmente no discurso anticomunista que começava a ganhar força nesse período. Para essa eleição foi criado um grupo político paulista, intitulado "Chapa Única por São Paulo Unido", com representantes do PRP e do PD que criaram uma frente em comum tendo em suas propostas, entre outras coisas, a instituição do sistema federativo republicano, voto secreto, autonomia plena dos Estados, restabelecimento do habeas corpus, ensino primário gratuito e obrigatório e especial atenção às classes trabalhadoras, entre outras coisas (SALONE, 2009, p. 212). OESP, desde a formação do grupo, sancionou seu apoio e passou a abrir grande espaço dentro de suas páginas para a divulgação de vários aspectos dessa coligação:

Achamos que S. Paulo deve apoiar a chapa unica, porque ella não se fez em attenção aos partidos, mas em attenção aos principios. Ella não se organisou para demonstrar o prestigio desta ou daquella agremiação, mas para defender, na Constituinte, um programma preciso. Esse programa é que provocou o nosso applauso e que justifica o appelo que fazemos ao povo paulista para que dê o seu voto áquella chapa. Indicamos, hontem, alguns pontos desse programma. O principal é o da manutenção da autonomia dos Estados dentro da federação braslieira. Desse depende a sorte da propria republica. Sem federação e sem autonomia dos Estados a republica estará morta. Nem a unidade nacional subsistirá. Se variosnucleos poderosos da opinião publica se reunem, calando resentimentos e divergências pessoaes, para commetter a delegados escolhidos, de commum accôrdo, a missão de defender esse programma, não é natural que se peça para esses delegados o apoio do povo paulista, que é um povo para o qual o systema republicano federativo tem a força e a virtude de um dogma? (OESP, Notas e Informações, 20/04/1933).

Tendo grande êxito, esse grupo conseguiu eleger 17 dos 22 representantes paulistas na Assembleia ${ }^{4}$. Embora a ação desse grupo não foi coesa dentro

\footnotetext{
${ }^{4}$ Entre esses eleitos, podem ser destacados o filho do ex-presidente Rodrigues Alves, o médico Oscar Rodrigues Alves; o líder católico Plinio Corrêa de Oliveira; o engenheiro e militar Mário Whately; o jurista José Carlos de Macedo Soares; membros tradicionais do PRP como João Sampaio, Cincinato Braga e Abelardo Vergueiro César e do PD como Antônio Carlos de Abreu Sodré, além da eleição da primeira mulher do Legislativo brasileiro, a médica Carlota Pereira de Queirós (PRADO, 1986, p. 133-136).
}

da Constituinte e, posteriormente, na Câmara dos Deputados, ainda sim tal agremiação possuiu força relativa nos trabalhos, sendo que o jornal manteve seu apoio durante todo o processo.

Além disso, embora a Constituição instituísse o voto direto para a escolha do novo presidente, a primeira eleição foi declarada como indireta, sendo que Getúlio Vargas foi mantido como presidente pela maioria dos congressistas e, assim, continuaria no cargo por mais quatro anos, sendo que o pleito de 1938 seria direto. A partir dessa resolução, vários estados seguiram essa base e, em São Paulo, no ano de 1935, Armando Salles de Oliveira também foi eleito para seguir no governo de São Paulo pela Assembleia Constituinte Paulista. OESP manteve a aproximação do periódico com a máquina estadual até fins de 1936, quando o governador renunciou ao cargo para preparar sua candidatura à presidência da República.

No entanto, essa eleição nunca ocorreu. Uma forte instabilidade política nos anos 1930 a nível mundial e, no caso brasileiro, agremiações com caráter bastante distintos e influenciadas por essas movimentações externas procuravam demarcar territórios e participar do debate político e social do país. Em 1932 foi criada a AIB, que inicialmente era um grupo de estudos em São Paulo intitulado Sociedade de Estudos Paulistas (SEP) e que, após a Revolução de 1932, passou a se firmar como uma espécie de partido político e representante dos ideais fascistas no Brasil (TRINDADE, 1979, p. 4). Seu principal líder foi o jornalista Plínio Salgado, que mobilizou células em várias partes do país e reuniu várias pessoas, sendo que muitos marchavam com uniformes (chamados popularmente de camisas-verdes) e com cumprimento próprio (o anagrama Anauê, com uma saudação parecida com as utilizadas pelos nazistas).

Como contraponto a esse grupo foi estruturada, em 1935, a ANL, agremiação formada por vários setores distintos (desde liberais até comunistas, passando por sindicatos e vários outros grupos ligados aos trabalhadores urbanos) que tinham como principal enfoque evitar a influência do fascismo no país e buscar melhorias nas condições de vidas dos grupos ali representados (PRESTES, 2008, p. 73-89). O confronto entre os blocos começou quase que instantaneamente, uma vez que a ANL passou a ser controlada cada vez mais pelos núcleos comunistas, com a presidência "de honra" ocupada pelo ex-tenente Luís Carlos Prestes, que 
gozava de grande prestígio popular por conta de sua participação na Coluna Prestes e que, nesse contexto, encontrava-se na União das Repúblicas Socialistas Soviéticas (URSS) (PRESTES, 2008, p. 99-122).

Embora os regimes fascistas ganhassem força na Europa, quem o governo temia em relação a influências externas era o comunismo, que também ganhava adeptos no Ocidente, principalmente, por conta da quebra da bolsa nos EUA, em 1929. Assim, para conter uma possível escalada comunista, o Executivo nacional decretou a ilegalidade da ANL em fins de 1935, fazendo com que as lideranças se organizassem para tentar um levante armado contra Vargas, fator que passou a ser conhecido pejorativamente como a Intentona Comunista (MOTTA, 2002, p. 7680). Em meio a esse turbilhão, a discussão sobre a próxima candidatura presidencial ganhava força e, além do nome de Armando Salles de Oliveira (cujo próprio colocara sua candidatura como de oposição) também surgiram outros dois candidatos: o ministro do Tribunal de Contas da União (TCU) e político paraibano (espécie de "herdeiro" político de João Pessoa), o possível candidato de Vargas, José de Américo Almeida, e o líder da AIB, Plínio Salgado.

O ano de 1937 estruturou-se com essas bases e o clima de inquietação por parte dos militares e de vários civis era cada vez mais intenso. Quase no fim do ano, vazou um documento organizado pelo capitão do Exército Olímpio Mourão Filho, e que viria a ser conhecido por Plano Cohen, cujo conteúdo externava um plano no qual o Brasil passaria por um novo ataque de comunistas que visavam instituir uma ditadura no país e afastar (e também executar) as principais lideranças políticas nacionais.

Embora a autenticidade da carta não foi comprovada no período, o clima criado foi suficiente para que, em 10 de novembro de 1937, Vargas desse um golpe em seu próprio mandato e instituísse um novo governo, homônimo ao comandado por Antônio Salazar em Portugal (PAULO, 1994, p. 50).

\section{REAÇÃO AO ESTADO NOVO}

Embora, a primeiro momento, OESP e a imprensa em geral foram favoráveis a tal movimentação (tendo em comum o discurso anticomunista), logo o periódico e a maioria dos jornais acabaram se voltando contra o novo governo.
Com o arbítrio do Estado (que ganhara feições muito próximas ao fascismo, sendo que a nova Constituição fora outorgada e coordenada pelo ex-ministro da Educação e Saúde e então ministro da Justiça, Francisco Campos), os opositores foram cada vez mais perseguidos e com um espaço cada vez menor para exporem opiniões contrárias ao governo. Júlio de Mesquita Filho foi preso inúmeras vezes até que, quase um ano após a instalação do regime de força varguista, rumou junto com Armando Salles de Oliveira e vários outros nomes para Paris, onde começou seu segundo período de exílio (CAPELATO; PRADO, 1980, p. 54-71), que duraria até 1943 e que o levaria ainda aos Estados Unidos e à Argentina.

Mesmo com o afastamento de seu diretor e principal nome, OESP continuou na oposição sob a liderança do irmão de Júlio de Mesquita Filho, Francisco Mesquita, até 1940 quando, a mando do interventor paulista Adhemar de Barros, o jornal foi invadido e perdeu sua autonomia, passando a ser controlado pelo regime ditatorial, sob a alegação de que existiam armas escondidas em sua redação (CAPELATO, 1988, p. 27). Além disso, por pressão do governo, o jornal foi quase todo vendido na íntegra para a União, sendo que praticamente toda a família Mesquita aceitou vender suas ações. Do exílio, o ex-diretor foi o único que não aceitou abrir mão de sua parte (SALONE, 2009, p. 254-264). Até o fim do Estado Novo, OESP passou a orbitar quase que integralmente na esfera estatal, não tendo praticamente influência alguma da família Mesquita em suas páginas.

Após tentar articular uma grande oposição a Vargas e passar por inúmeros problemas financeiros nos países pelos quais morou no exílio, Júlio de Mesquita Filho resolveu voltar em 1943 ao Brasil, mesmo sob a possibilidade de permanecer preso. Não chegou a ser detido, mas foi obrigado a ficar recluso na fazenda da família, em Louveira, e de não manter contatos políticos. O fim do governo de Vargas viria quase dois anos depois, quando os últimos instantes da Segunda Guerra Mundial levaram o presidente brasileiro a um paradoxo: com um regime muito próximo do modelo dos países do Eixo (em especial, a Alemanha e a Itália), o Brasil entrou diretamente no combate em 1942 para apoiar os Aliados (principalmente por pressão dos Estados Unidos), grupo que combatia os regimes fascistas e que ainda continha a URSS ao seu lado. 
Com a vitória praticamente assegurada desse grupo, os próceres do Estado Novo passaram a direcionar o processo de democratização do país, após quase oito anos de ditadura. Nesse meio termo, alguns atos de contestação ao regime já começavam a se estruturar como, por exemplo, a publicação do Manifesto dos Mineiros em 1943 (documento organizado por um grupo de políticos opositores ao regime, sintetizando uma série de críticas à Vargas e que procurou justificar porque que os signatários do grupo eram contrários ao seu governo), o I Congresso Brasileiro de Escritores, realizado em janeiro de 1945, em São Paulo, com uma perspectiva contra a censura (o congresso foi organizado pela Associação Brasileira de Escritores, criada em 1942 exatamente com a ideia de que esses profissionais se unissem contra o controle imposto pelo regime de força) e, principalmente, a entrevista publicada, em fevereiro, no CM, de José Américo de Almeida, dada ao jornalista Carlos Lacerda e, na qual, criticou vivamente vários aspectos relacionados ao governo e ao próprio presidente (de quem fora aliado, sendo um dos organizadores da Revolução de 30, interventor na Paraíba e ministro dos Transportes nos primeiros anos do governo Vargas):

Embora não queiramos sofrer influências estranhas, evidentemente o Brasil tem de receber os reflexos da guerra, do caráter ideológico da guerra, que é uma luta pela sobrevivência e purificação da democracia. A guerra, com todos os seus males, é uma grande oportunidade para nos organizarmos e ocuparmos o espaço territorial do nosso País, desenvolvermos a exploração de nossas riquezas (...) No decorrer de tantos anos, e a partir de 1937, com uma soma de poderes que nenhum governante enfeixou no Brasil, ainda mais sem abalos da ordem pública, o Governo tenha procurado encaminhar alguns problemas. Por exemplo, o da siderurgia (...) Houve, no entanto, o abandono de iniciativas primárias, principalmente aquelas relacionadas com a produção e o transporte. É possível que tenha prevalecido a preocupação de impressionar com empreendimentos de maior vulto, de modo a justificar a fisionomia do regime. Mas, se tais empreendimentos absorveram atenções e recursos, não contribuíram para preferir atividades mais acessíveis e imediatas, destinadas, inclusive, a lastrear e garantir o êxito daquelas de mais remotos resultados. É, em suma, um governo que acaba exausto e impotente, apesar dos apelos imoderados à emissão de papel-moeda e da sangria fiscal (...) (CM, A SITUAÇÃO DECLARAÇÕES DO SR. JOSÉ AMÉRICO, 22.02.1945)

Após o fim do Estado Novo em 1945, OESP voltou a ser controlado pela família Mesquita, com o auxílio de vários bancos e entidades paulistas que se mobilizaram para recolher ativos, em quantidade suficiente para comprar as ações do governo e devolvê-las aos antigos donos. Tal fator é bastante importante, pois esses grupos passaram a participar diretamente da organização do jornal, principalmente o banqueiro Gastão Vidigal, fundador do Banco Mercantil de São Paulo e principal financiador dessa movimentação para devolver o jornal à família Mesquita (SALONE, 2009, p. 297).

Com o controle do OESP novamente em mãos, Júlio de Mesquita Filho retomou seus textos abordando a política de maneira bastante intensa. Em seu primeiro editorial após seu retorno (Notas e Informações, de 08/12/1945), ele expôs um texto exaltando a democracia e criticando (não de maneira intensa, apenas protocolarmente) a ditadura e exaltando a figura de Eduardo Gomes, ficando na expectativa para que ele vencesse a eleição presidencial (embora não atacasse diretamente o general Dutra, o outro candidato):

Vindo de uma ditadura, que não só subverteu as instituições como pôs em perigo a estrutura social do pais, contaminando todos os ramos da atividade publica com os males da corrupção e provocando uma verdadeira desagregação das forças morais, o Brasil precisa colocar, nos postos de comando e nas casas legislativas, cidadãos genuinamente democraticos, inteiramente limpos de conivencia com o regime extinto, capazes de, pela sua formação espiritual, pela sua educação civica e pela sua atuação politica no passado, levar a cabo, com decisão e patriotismo, a obra de remodelação juridica e principalmente, social, a que nos temos de entregar se quisermos adquirir, em face das outras nações, o prestigio de outrora e assegurar aos que vivem dentro do Territorio Nacional uma vida que seja para todos, poderosos e humildes, ricos e pobres, a expressão maxima da dignidade humana (...) (OESP, Notas e Informações, 08/12/1945).

\section{CONCLUSÃO}

Em linhas gerais, o jornalista paulista reassumiu o comando de seu periódico mantendo seu habitus e 
marcado pelo longo exílio durante o Estado Novo, a primeiro momento fora e depois dentro de seu próprio país, acumulando imensas críticas e mágoas contra Getúlio Vargas e seu entorno. Em relação aos aspectos da cultura política de Júlio de Mesquita Filho, pode-se destacar os seguintes aspectos: liberalismo econômico (embora muito ligado à agricultura, buscava modernizações para OESP e era entusiasta do desenvolvimento industrial), progressismo educacional (ainda continuava um árduo defensor do desenvolvimento universitário e do ensino em geral no Brasil, bem como de uma maior valorização cultural) e conservadorismo político (opositor à Vargas, buscava o resgate dos aspectos positivos das antigas instituições brasileiras, inclusive do próprio período imperial, não propondo novas formas de estruturação política).

$\mathrm{O}$ editor do jornal paulista voltara ao seu tradicional posto e no qual se sentia mais à vontade, procurado informar e, principalmente, formar as opiniões de seus leitores, defendendo aspectos bastante importantes para uma melhor compreensão do período em causa. No ano de 1945 OESP reintegrava-se ao campo político ocupando o espaço de oposição, trazendo seu capital estruturado por uma vivência de 70 anos, com uma postura sempre bastante participativa sobre a política, tanto a nacional quanto a estadual. E, acompanhando as perspectivas de seu principal acionista, tal inserção ocorreu com a cultura política liberal, dentro das condicionantes e perspectivas apresentadas na trajetória de Júlio de Mesquita Filho.

Em linhas gerais, é importante indicar que OESP consolidou-se como um jornal bastante ativo e combativo no campo político, indicando uma participação que transcendia à construção da informação para seus leitores, buscando participar, efetivamente, das movimentações ligadas às instituições brasileiras em fins do século XIX e início do século XX.

Principalmente após a direção ser orientada por Júlio de Mesquita Filho, o traço combativo da publicação ficou ainda mais intenso, oscilando entre os valores do jornalista (como os traços evolucionistas e liberais) e as tomadas de posições políticas (como as posturas a favor e contra Vargas, em momentos distintos).

Por fim, é possível concluir que a estruturação do jornal esteve vincada com os valores de Júlio de Mesquita e, principalmente, de Júlio de Mesquita Filho. Esse, em suma, buscou estruturar o jornal não somente como um meio de informação, mas também de intervenção política e também sociocultural, propondo criar mecanismos para acelerar a evolução do Brasil, dentro dos princípios ideológicos de seu proprietário. Com esses princípios, a publicação retomaria suas coberturas jornalísticas e intervenções no campo político em um novo contexto, marcado pelo fim do Estado Novo e início de um período democrático no país.

\section{REFERÊNCIAS}

Arquivo Correio Paulistano, Edições de 1870 a 1920.

A Província de S. Paulo, Edições de 1873 a 1890.

O Estado de S. Paulo, Edições de 1890 a 1945.

AZEVEDO, Fernando de. A educação na encruzilhada: problemas e discussões. Inquérito para $O$ Estado de $S$. Paulo. 2 ed. São Paulo: Edições Melhoramentos, 1960.

BORGES, Vavy P. Getúlio Vargas e a Oligarquia Paulista - História de uma esperança e de muitos desenganos através dos jornais da oligarquia: 1926-1932. São Paulo: Brasiliense, 1979.

CALDEIRA, Jorge. Júlio Mesquita e seu tempo. O jornal do prelo, locomotores da república (1927/1862-1897). São Paulo: Mameluco, 2015.

CAPELATO, Maria H. R. Os arautos do liberalismo: 19201945. São Paulo: Brasiliense, 1989.

CAPELATO, Maria H. R; PRADO, Maria L. O Bravo Matutino: imprensa e ideologia: o jornal O Estado de São Paulo. São Paulo: Alfa-Ômega, 1980.

CASALECCHI, José E. O Partido Republicano Paulista: política e poder (1889-1926). São Paulo: Brasiliense, 1987.

FERREIRA, Antônio C. A epopéia bandeirante: letrados, instituições, invenção histórica (1870-1940). São Paulo: Editora UNESP, 2002.

LEAL, Victor N. Coronelismo, enxada e voto. O município e o regime representativo no Brasil. $7^{\circ}$ ed. São Paulo: Companhia das Letras, 2012.

MESQUITA, Júlio de. A guerra (1914-1918). São Paulo: O Estado de S. Paulo: Editora Terceiro Nome, 2002, 4 v.

MESQUITA FILHO, Júlio de. A crise nacional: reflexões em torno de uma data. O Estado de S. Paulo, São Paulo, 15 de novembro de 1925.

MESQUITA FILHO, Ruy. Cartas do exílio: a troca de correspondência entre Marina e Júlio de Mesquita Filho. São Paulo: Albatroz; Loqui; Terceiro Nome, 2006. 
MOTTA, Rodrigo Patto de Sá. Em guarda contra o "Perigo Vermelho": o anticomunismo no Brasil (1917-1964). São Paulo, Perspectiva: FAPESP, 2002.

PAULO, Heloísa. Estado Novo e propaganda em Portugal e no Brasil. O SPN/SNI e o DIP. Coimbra: Livraria Minerva, 1994 (Coleção Minerva-História 11).

PONTES, José A. V. Julio de Mesquita Filho. Recife: Fundação Joaquim Nabuco, Editora Massangana, 2010 (Coleção Educadores).

PRADO, Maria L. C. A Democracia Ilustrada (O Partido Democrático de São Paulo, 1926-1934). São Paulo: Editora Ática, 1986 (Ensaios; 115).

PRESTES, Anita L. Luiz Carlos Prestes e a Aliança Nacional Libertadora: os caminhos da luta antifascista no Brasil (1934/35). São Paulo: Brasiliense, 2008.

SALONE, Roberto. Irredutivelmente liberal: política e cultura na trajetória de Júlio de Mesquita Filho. Rio de Janeiro: Albatroz Editora, 2009.

SODRÉ, Nelson W. A história da imprensa no Brasil. Rio de Janeiro: Civilização Brasileira, 1966.

TASCHNER, Gisela. Folhas ao vento: Análise de um conglomerado jornalístico no Brasil. Rio de Janeiro: Paz e Terra, 1992.

TRINDADE, Helgio. Integralismo: o fascismo brasileiro na década de 30. Rio de Janeiro: DIFEL, 1979.

Recebido em: 08.07.2017

Aceito em: 18.09.2017 